\title{
The Effect of Leader-Member Exchange "LMX" on Employee Turnover Intent: An Applied Study on the Telecommunication Sector in Egypt
}

\author{
Lara Ayman Abu Bakr Shaalan ${ }^{1}$, Abdel Moniem Elsaid ${ }^{1} \&$ Eahab Elsaid $^{2}$ \\ ${ }^{1}$ Faculty of Commerce, Ain Shams University, Egypt \\ 2 Odette School of Business, University of Windsor, Canada \\ Correspondence: Eahab Elsaid, Odette School of Business, University of Windsor, Canada. E-mail: \\ elsaid@uwindsor.ca
}

Received: September 7, 2018

Accepted: November 12, 2018

Online Published: November 20, 2018

doi:10.5430/jbar.v8n1p1

URL: https://doi.org/10.5430/jbar.v8n1p1

\begin{abstract}
The paper examines whether the Leader-member exchange (LMX) theory has an effect on the employee turnover intent in the presence of intercultural competence. Our sample consists of 319 employees working in the telecommunications sector in Egypt. The dependent variable is employee turnover and the independent variable is LMX, where LMX as a variable is measured by four components: affect, loyalty, contribution and professional respect. We used intercultural competence as the moderating variable. Intercultural competence is measured by nine components: cross cultural empathy, self-efficacy, willingness to engage, cross cultural openness, emotional self-regulation, self-monitoring, tolerance for ambiguity, low need for cognitive and cognitive flexibility. We used Cronbach's alpha, path analysis and path regressions in our statistical analysis. Our results showed a significant positive relationship between LMX and employee turnover intent and an indirect relationship between LMX and employee turnover intent in the presence of intercultural competence.
\end{abstract}

Keywords: leader-member exchange, employee turnover intent, intercultural competence, telecommunications sector, Egypt

\section{Introduction}

Previous research indicated that the quality of leadership does affect employee turnover decisions (Jordan \& Troth, 2011; Morrow, Suzuki, Crum, Ruben, \& Pautsch, 2005; Gerstner \& Day, 1997). The Leader-member exchange theory (LMX) identifies the components that play a role in the leader-subordinate relationship (Liden, Sparrowe, \& Wayne, 1997; Graen \& Uhl-Bien, 1995) which in turn help explain the framework on which leadership behavior affects employee turnover (Cropanzano, Dasborough, \& Weiss, 2017; Joo, 2010; Morrow et al., 2005). Some previous studies were unable to find a correlation between LMX and employee turnover intent (Schyns, Torka, \& Gossling, 2007; Vecchio \& Norris, 1996; Vecchio, 1985). However, other previous studies found that LMX is negatively related to employee turnover intent (Adil \& Awais, 2016; Abu Elanain, 2014; Saeed, Waseem, Sikander, \& Rizman, 2014; Joo, 2010). As a result, there are inconsistencies in previous studies regarding the relationship between LMX and employee turnover intent. Our study aims to examine the link between LMX and employee turnover intent while using intercultural competence as a mediating variable. The goal is to determine if intercultural competence mediates the relationship between LMX and employee turnover intent.

Conducting the study in Egypt is particularly useful since Egypt has high turnover rates especially in retail, telecommunications and banking sectors (El Farghaly \& Fouad, 2013). The turnover of highly skilled employees is a significant problem in the Egyptian telecommunications sector (El Farghaly \& Fouad, 2013). High turnover rates will lead to a problem with employee retention for the firms. High employee turnover rates will also lead to costs associated with the replacement of the employee skill set and intellectual capital, costs for training, loss of effectiveness and productivity, and time taken by new employees to acclimate to organizational values and cultures (Arishi, Elsaid, Dawi, \& Elsaid, 2018; Abbasi \& Hollman, 2000). Other costs associated with employee turnover are fees for recruiting agencies, advertising costs for the vacant positions and administrative costs associated with screening and interviewing candidates (Schyns et al., 2007). 
Most of the previous research on the relationship between LMX and employee turnover intent focused on Western countries (Cropanzano et al., 2017; Zhang, Lam, \& Deng, 2017; Flickinger, Allscher, \& Fiedler, 2016; Kwak \& Choi, 2015; Saeed et al., 2014; Jordan \& Troth, 2011; Joo, 2010; Harris, Kacmar, \& Witt, 2005; Morrow et al., 2005; Gerstner \& Day, 1997). There is a gap in the research when it comes to examining the effect of LMX on employee turnover intent in non-Western countries. The previous research that examined the LMX - employee turnover intent relationship in non-Western countries is scarce: Ali, Lodhi, Orangzab, Raza, \& Ali (2018) and Adil \& Awais (2016) examined this relationship in an Asian country, Pakistan. We only found one previous study (Abu Elanain, 2014) that examined this relationship in a Middle Eastern country: UAE. To the best of our knowledge, our study is the first study that examines the relationship between LMX and employee turnover intent in Egypt.

Of all the previous studies that we were able to find, our study is the first to use intercultural competence as a mediating variable when examining the relationship between LMX and employee turnover intent. Jordan \& Troth (2011) used followers' emotional intelligence and job satisfaction as mediating variables. Abu Elanain (2014) used role conflict, job satisfaction and organizational commitment as mediating variables. Flickinger et al., (2016) used job satisfaction as a mediating variable. Ali et al., (2018) used work engagement and job satisfaction as mediating variables.

Our study adds to the existing literature by examining how high quality LMX helps to reduce employee leave intent in a Middle Eastern country, Egypt. In addition, the study is the first of its kind, to the best of our knowledge, to examine the mediating role of intercultural competence on the relationship between LMX and turnover intent. In doing so, the study attempts to generalize the LMX framework by examining it in a (never before examined) non-Western country, Egypt.

\section{LMX theory}

The LMX theory studies the quality of the relationship between supervisors and their subordinates (Mardanov, Sterrett, \& Baker, 2007; Harris et al., 2005). The LMX theory reflects the interpersonal relationship between a supervisor and an employee (Schyns et al., 2007). This relationship that results from exchanges between supervisors and subordinates can be a high quality relationship (i.e., high LMX or in-group) that reflects loyalty, trust and respect or can be a low quality relationship (i.e., low LMX or out-group) that reflects a lack of loyalty, mistrust and no respect (Morrow et al., 2005).

Previous research is split on whether LMX is multidimensional (Liden \& Maslyn, 1998) or unidimensional (Duncan \& Herrera, 2014). The argument for the multidimensionality of LMX can be derived from Role theory and Social Exchange theory. Role theory implies that all individuals have defined roles and hold expectations of themselves and others based on those roles (Harris, Harris, \& Eplion, 2007). Role theory was used to build the theoretical foundation of LMX (Graen, 1976). Supervisors and subordinates have social interactions that result in supervisors assigning important organizational roles to strong performing employees and assigning less important organizational roles to employees with weaker performance. This will inevitably lead the employees who were assigned important roles to have a high quality LMX relationship (that includes loyalty, trust and respect) with their supervisors. On the other hand, the employees who were assigned less important roles will have a low quality LMX relationship (that includes lack of loyalty, mistrust and no respect) with their supervisors.

As implied from the "exchange" in the leader-member exchange theory, LMX can be considered to be a subset of the Social Exchange theory (Sparrowe \& Liden, 1997). LMX theory shows how supervisors develop exchange relationships with their subordinates over time (Lee, 2005). Previous research in the Social Exchange theory has identified many material and non-material things that can be exchanged such as: friendship, advice and workflow (Sparrowe \& Liden, 1997; Krackhardt, 1990) which implies that the exchange relationships between supervisors and subordinates seem to be multidimensional. As a result, it appears that both the roles and exchanges between supervisors and subordinates seem to have multiple dimensions.

Dienesch \& Liden (1986) proposed that the LMX is composed of three main dimensions: affect, contribution and loyalty. Liden et al. (1997) found that the mutual liking between a supervisor and a subordinate was a better predictor of LMX than the supervisor's assessment of the subordinate's performance. Previous studies indicated that loyalty was a determinant in deciding which kind of tasks are assigned to subordinates (Scandura, Graen, \& Novak, 1986). Dienesch \& Liden (1986) admit that there could be other LMX dimensions besides affect, contribution and loyalty. Trust, openness, respect and honesty are among those other dimensions. Liden \& Maslyn (1998) added a fourth dimension to LMX: professional respect. 


\section{Employee turnover intent}

Previous research documented the adverse effects of voluntary turnovers on organizations, regardless of the industry. Retaining qualified employees is a crucial challenge that most organizations face. Griffeth, Hom, \& Gaertner (2000) show that organizational predictors such as, work engagement, job satisfaction and organizational commitment have a strong association with employee turnover intent and actual turnovers. Organizational researchers examined employee turnover intent rather than actual employee turnovers for several reasons: it is easier to collect, it can be collected from current employees and it provides a continuous measure which helps avoid sample bias (Kim, Lee, \& Carlson, 2010; Bluedorn, 1982). Dalessio, Silverman, \& Schuck (1986) indicate that employee turnover intent is the most reliable predictor of employee turnover behavior.

\section{The relationship between LMX theory and employee turnover intent}

Previous research has produced mixed results when it comes to the relationship between LMX quality and employee turnover intent. Collins (2010) states that "the exact nature of the relationship between LMX and turnover intent remains equivocal." Some studies have found a linear relationship between LMX and employee turnover intent. That is to say, subordinates who have low quality LMX relationships with their supervisors are more likely to show a greater intent to quit than subordinates who have high quality LMX relationships with their supervisors (Schyns et al., 2007; Gerstner \& Day, 1997). As a result, when supervisors develop high quality LMX relationships with their subordinates, this will reduce the subordinates' propensity to quit. In this case, it is of the utmost importance for supervisors to cultivate a high quality LMX relationship with their subordinates in order to minimize employee turnover intent.

Other studies have found a U-shaped curvilinear relationship between LMX quality and employee turnover intent (Kim et al., 2010; Harris et al., 2005; Morrow et al., 2005). That is to say, employee turnover intent is lowest when LMX quality is moderate and is highest when LMX quality is both good and bad. Morrow et al., (2005) reaffirm that employee turnover intent is highest for both high and low quality LMX relationships.

\section{Intercultural competence}

The definitions of intercultural competence are varied. The reason being that intercultural competence has been studied by researchers in multiple disciplines such as: communications (Lustig \& Koester, 2010), leadership (Inceoglu \& Bartram, 2012), education (Cushner \& Mahon, 2002), international business (Lloyd \& Härtel 2010), and psychology (Chiu \& Hong, 2005). Researchers studied the concept of intercultural competence without building on the findings of their counterparts from other disciplines. For example, Fantini (2009) defines intercultural competence as "a complex of abilities needed to perform effectively and appropriately when interacting with others who are linguistically and culturally different from oneself." Johnson, Lenartowicz, \& Apud (2006) define intercultural competence as "an individual's effectiveness in drawing upon a set of knowledge, skills, and personal attributes in order to work successfully with people from different national cultural backgrounds at home or abroad."

Prior research has identified more than 30 models for intercultural competence and in excess of 300 personal characteristics (Spitzberg \& Chagnon, 2009; Johnson et al., 2006). In this study, the authors chose the following nine personal characteristics/components in order to measure intercultural competence: cross cultural empathy (Wang et al., 2003), self-efficacy (Ang, Van Dyne, Koh, \& Ng, 2007; Luszczynska, Scholz, \& Schwarzer, 2005; Schwarzer \& Jerusalem, 1995), willingness to engage (Ross, 2008; McCroskey,1992), cross cultural openness (Gudykunst \& Kim, 2003; Webster \& Kruglanski, 1994), emotional self-regulation (Gross \& John, 2003), self-monitoring (Ang et al., 2007), tolerance for ambiguity (Ang et al., 2007; Webster \& Kruglanski, 1994), low need for cognitive (Webster \& Kruglanski, 1994) and cognitive flexibility (Ross, Thornson, McDonald, \& Arrastia, 2009; Ross, 2008; Webster \& Kruglanski, 1994).

5. The mediating effect of intercultural competence

Scandura (1999) indicated that the inconsistency in the previous research between the LMX and different organizational outcomes (such as employee turnover intent) could be due to previous researchers neglecting one or more mediating variables in their studies. Hollander (1978) called on researchers to examine the roles of different mediating variables on the relationship between LMX and different organizational outcomes. To the best of our knowledge, the current study is the first to consider intercultural competence as a mediating variable between LMX and employee turnover intent. 


\section{Research Hypothesis, Data Collection and Sample Selection}

1. Research hypothesis

H1: There is a direct positive relationship between LMX and employee turnover intent

$\mathrm{H} 2$ : There is an indirect relationship between LMX and employee turnover intent in the presence of intercultural competence

2. Study sample

The sample includes Egyptian telecommunications sector employees working in three organizations: Vodafone, Orange and Etisalat. The data was collected using the method of convenience.

$$
\mathrm{n}=\frac{\mathrm{z}^{2} * \mathrm{~s}^{2}}{\mathrm{e}^{2}}(\text { Yamane, 1967, p. 581) }
$$

where:

e: allowable error,

s: sample standard deviation,

n: sample size.

z: the confidence level in standard degrees.

If $\mathrm{z}=2$ for a $95 \%$ confidence level and $\mathrm{s}^{2}=$ population variance $=0.25$ assuming the worst case when the population variance is at its maximum which occurs when the population proportion of variability is equal to 0.5 . If the population proportion is to be estimated within an error of 0.05 at a $95 \%$ confidence level, the needed sample size will be:

$\mathrm{n}=2^{2}(0.25) /(0.05)^{2}=400$

The study sample should consist of 400 employees from the three telecommunication firms in Egypt, from the beginning of June 2017 until the end of October 2017. However, only 319 questionnaire forms were returned.

3. Descriptive statistics

The sample is divided as follows:

Organizations: 117 respondents were Vodafone employees, 70 were Etisalat employees and 132 were Orange employees. Gender: 225 respondents were males and 94 respondents were females.

Age: 133 respondents were between the ages of 21 and 30. One hundred and eighty six respondents were between the ages of 31 and 40. No respondents were between the ages of 41 and 50 or older than 50. Education: 281 respondents had a Bachelor degree and 38 respondents had a masters' level degree. Experience: 63 respondents had between 1 and 3 years of experience, 137 respondents had between 4 and 7 years of experience, 80 respondents had between 8 and 10 years of experience, 39 respondents had more than 10 years of experience.

\section{Measures}

The Appendix (available from authors) includes the questionnaire that was distributed to the 400 employees from the three telecommunication firms in Egypt. The questionnaire partly uses the LMX-MDM scale and the Discovering Diversity Profile (Duncan \& Herrera, 2014; Luszczynska et al., 2005; Liden \& Maslyn, 1998; Schwarzer \& Jerusalem, 1995). It was scaled on a 5-point Likert scale, ranging from "Strongly Disagree" to "Strongly Agree". LMX, the independent variable, is represented by four components: affect (Q1-Q3), loyalty (Q4-Q6), contribution (Q7-Q9), and professional respect (Q10-Q12). Intercultural competence, the moderating variable, is represented by nine components: cross cultural empathy (Q13-Q27), self-efficacy (Q28-Q43), willingness to engage (Q44-Q64), cross cultural openness (Q65-Q81), emotional self-regulation (Q82-Q93), self-monitoring (Q94-Q111), tolerance for ambiguity (Q112-Q120), low need for cognitive (Q121-Q138) and cognitive flexibility (Q139-Q156). Employee turnover intent, the dependent variable, is represented as one dimension (Q157-Q159).

We measure the reliability and validity of the questionnaire using Cronbach's alpha. The closer the Cronbach's alpha coefficient is to 1 the better. The Cronbach's alpha coefficient for the LMX variable is 0.915 , for the intercultural competence variable is 0.993 and for the employee turnover intent variable is 0.745 . The above results indicate that the questionnaire used is both reliable and valid. 


\section{Methodology}

We use a path model set of structural equations to test the hypothesis. The following path regressions will be used:

$$
\begin{gathered}
\text { Employee Turnover Intent }=\beta_{01}+\beta_{11} L M X \\
\text { Employee Turnover Intent }=\beta_{02}+\beta_{12} \text { Intercultural Competence Component } \\
\text { Intercultural Competence Component }=\beta_{03}+\beta_{13} L M X
\end{gathered}
$$

There will be nine path model sets of structural equations, one for each component of the intercultural competence variable. All nine path model sets have the same equation 1, while equation 2 and 3 will change by changing the intercultural competence component (cross cultural empathy, self-efficacy, willingness to engage, cross cultural openness, emotional self-regulation, self-monitoring, tolerance for ambiguity, low need for cognitive and cognitive flexibility). These path regressions (path estimation equations) will be estimated using maximum likely-hood estimates and will be presented using path analysis (Wright, 1960).

Land (1969) explains the path analysis method as "applies to only sets of relations among variables which are linear, additive and causal." In order to use the created variables in path analysis they must be used in their raw score form. That is to say, each variable is created as an average score of the questions measuring it. For example, the LMX variable is created as an average score of affect (Q1-Q3), loyalty (Q4-Q6), contribution (Q7-Q9), and professional respect (Q10-Q12). Each of the components is created as an average score of questions measuring it.

Table 1. Descriptive statistics for employee turnover intent, LMX and the nine components of intercultural competence

\begin{tabular}{llllll}
\hline Variable & $\mathrm{N}$ & Min & Max & Mean & $\begin{array}{l}\text { Standard } \\
\text { Deviation }\end{array}$ \\
\hline Affect & 319 & 1.33 & 4.67 & 3.2375 & 0.94756 \\
Loyalty & 319 & 1.33 & 4.67 & 3.2539 & 0.89799 \\
Contribution & 319 & 1.33 & 4.67 & 3.2038 & 0.98553 \\
Professionalism & 319 & 1.33 & 4.67 & 3.3072 & 0.90866 \\
Cross-Cultural empathy & 319 & 1.33 & 4.67 & 3.2456 & 0.91495 \\
Self-efficacy & 319 & 1.53 & 4.27 & 3.2788 & 0.84692 \\
Willingness to Engage & 319 & 1.56 & 4.25 & 3.3366 & 0.84519 \\
Cross cultural openness & 319 & 1.48 & 4.19 & 3.3127 & 0.83653 \\
Emotional self-regulation & 319 & 1.65 & 4.29 & 3.3389 & 0.82999 \\
Self-Monitoring & 319 & 1.42 & 4.33 & 3.2928 & 0.84307 \\
Tolerance for ambiguity & 319 & 1.50 & 4.28 & 3.3008 & 0.84492 \\
Low need for cognitive & 319 & 1.56 & 4.44 & 3.3622 & 0.84760 \\
Cognitive flexibility & 319 & 1.61 & 4.22 & 3.3206 & 0.83479 \\
Employee Turnover Intent & 319 & 1.67 & 4.22 & 3.3063 & 0.83126 \\
LMX & 319 & 1.00 & 4.67 & 3.3584 & 0.96482 \\
\hline
\end{tabular}

\section{Findings}

1. Cross-cultural empathy

$$
\begin{gathered}
\text { Employee Turnover Intent }=\beta_{01}+\beta_{11} L M X \\
\text { Employee Turnover Intent }=\beta_{02}+\beta_{12} \text { Cross }- \text { Cultural empathy } \\
\text { Cross }- \text { Cultural empathy }=\beta_{03}+\beta_{13} \text { LMX }
\end{gathered}
$$


Table 2. Path regressions of the cross-cultural empathy component of intercultural competence as the mediating variable between LMX and employee turnover intent

\begin{tabular}{llll}
\hline Model & Estimate & P-Value & $\begin{array}{l}\text { Standard Error of the } \\
\text { Estimate }\end{array}$ \\
\hline Employee Turnover Intent $\rightarrow$ LMX & 0.479 & 0.000 & 0.131 \\
$\begin{array}{l}\text { Employee Turnover Intent } \rightarrow \text { Cross-cultural } \\
\text { Empathy }\end{array}$ & 0.514 & 0.000 & 0.130 \\
Cross-cultural Empathy $\rightarrow$ LMX & 0.978 & 0.000 & 0.014
\end{tabular}

Table 2 shows that LMX has a direct significant positive effect on employee turnover intent. LMX has a direct significant positive effect on cross-cultural empathy. Cross-cultural empathy has a direct significant effect on employee turnover intent. As a result, LMX has an indirect significant positive effect on employee turnover intent through cross-cultural empathy. This effect is equal to $0.514 * 0.978=0.503$. $\mathrm{R}^{2}$ for employee turnover intent is $76 \%$.

2. Self-efficacy

$$
\begin{gathered}
\text { Employee Turnover Intent }=\beta_{01}+\beta_{11} L M X \\
\text { Employee Turnover Intent }=\beta_{02}+\beta_{12} \text { Self }- \text { Efficacy } \\
\text { Self }- \text { Efficacy }=\beta_{03}+\beta_{13} \mathrm{LMX}
\end{gathered}
$$

Table 3. Path regressions of the self-efficacy component of intercultural competence as the mediating variable between LMX and employee turnover intent

\begin{tabular}{llll}
\hline Model & Estimate & P-Value & $\begin{array}{l}\text { Standard Error of the } \\
\text { Estimate }\end{array}$ \\
\hline Employee Turnover Intent $\rightarrow$ LMX & 0.204 & 0.116 & 0.130 \\
Employee Turnover Intent $\rightarrow$ Self-Efficacy & 0.795 & 0.000 & 0.129 \\
Self-Efficacy $\rightarrow$ LMX & 0.978 & 0.000 & 0.014 \\
\hline
\end{tabular}

Table 3 shows that LMX has no direct significant effect on employee turnover intent. LMX has a direct significant positive effect on self-efficacy. Self-efficacy has a direct significant positive effect on employee turnover intent. As a result, LMX has an indirect significant positive effect on employee turnover intent through self-efficacy. This effect is equal to $0.795 * 0.978=0.778$. $\mathrm{R}^{2}$ for employee turnover intent is $77 \%$.

3. Willingness to engage

$$
\begin{gathered}
\text { Employee Turnover Intent }=\beta_{01}+\beta_{11} L M X \\
\text { Employee Turnover Intent }=\beta_{02}+\beta_{12} \text { Willingness to Engage } \\
\text { Willingness to Engage }=\beta_{03}+\beta_{13} \mathrm{LMX}
\end{gathered}
$$

Table 4. Path regressions of the willingness to engage component of intercultural competence as the mediating variable between LMX and employee turnover intent

\begin{tabular}{llll}
\hline Model & Estimate & P-Value & $\begin{array}{l}\text { Standard Error of the } \\
\text { Estimate }\end{array}$ \\
\hline $\begin{array}{l}\text { Employee Turnover Intent } \rightarrow \text { LMX } \\
\begin{array}{l}\text { Employee Turnover Intent } \rightarrow \text { Willingness } \\
\text { to Engage }\end{array}\end{array}$ & 0.319 & 0.019 & 0.136 \\
Willingness to Engage $\rightarrow$ LMX & 0.974 & 0.000 & 0.137 \\
\end{tabular}

Table 4 shows that LMX has a direct significant positive effect on employee turnover intent. LMX has a direct significant positive effect on willingness to engage. Willingness to engage has a direct significant effect on employee turnover intent. As a result, LMX has an indirect significant positive effect on employee turnover intent through willingness to engage. This effect is equal to $0.684 * 0.970=0.663$. $\mathrm{R}^{2}$ for employee turnover intent is $77 \%$. 
4. Cross-cultural openness

$$
\begin{gathered}
\text { Employee Turnover Intent }=\beta_{01}+\beta_{11} L M X \\
\text { Employee Turnover Intent }=\beta_{02}+\beta_{12} \text { Cross }- \text { cultural Openness } \\
\text { Cross }- \text { cultural Openness }=\beta_{03}+\beta_{13} \mathrm{LMX}
\end{gathered}
$$

Table 5. Path regressions of the cross-cultural openness component of intercultural competence as the mediating variable between LMX and employee turnover intent

\begin{tabular}{llll}
\hline Model & Estimate & P-Value & $\begin{array}{l}\text { Standard Error of the } \\
\text { Estimate }\end{array}$ \\
\hline $\begin{array}{l}\text { Employee Turnover Intent } \rightarrow \text { LMX } \\
\text { Employee Turnover Intent } \rightarrow \text { Cross-cultural }\end{array}$ & 0.968 & 0.000 & 0.207 \\
Openness & 0.289 & 0.076 & 0.208 \\
Cross-cultural Openness $\rightarrow$ LMX & 0.958 & 0.000 & 0.030 \\
\hline
\end{tabular}

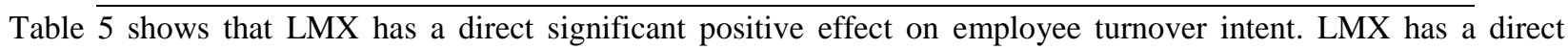
significant positive effect on cross-cultural openness. However, cross- cultural openness does not have a direct significant effect on employee turnover intent. As a result, LMX does not have an indirect significant effect on employee turnover intent through cross-cultural openness. $\mathrm{R}^{2}$ for employee turnover intent is $81 \%$.

5. Emotional self-regulation

$$
\begin{gathered}
\text { Employee Turnover Intent }=\beta_{01}+\beta_{11} L M X \\
\text { Employee Turnover Intent }=\beta_{02}+\beta_{12} \text { Emotional Self }- \text { regulation } \\
\text { Emotional Self }- \text { regulation }=\beta_{03}+\beta_{13} \text { LMX }
\end{gathered}
$$

Table 6. Path regressions of the emotional self-regulation component of intercultural competence as the mediating variable between LMX and employee turnover intent

\begin{tabular}{llll}
\hline Model & Estimate & P-Value & $\begin{array}{l}\text { Standard Error of the } \\
\text { Estimate }\end{array}$ \\
\hline $\begin{array}{l}\text { Employee Turnover Intent } \rightarrow \text { LMX } \\
\begin{array}{l}\text { Employee Turnover Intent } \rightarrow \text { Emotional } \\
\text { self-regulation }\end{array}\end{array}$ & 0.448 & 0.000 & 0.121 \\
Emotional self-regulation $\rightarrow$ LMX & 0.551 & 0.000 & 0.120 \\
\hline
\end{tabular}

Table 6 shows that LMX has a direct significant positive effect on employee turnover intent. LMX has a direct significant positive effect on emotional self-regulation. Emotional self-regulation has a direct significant effect on employee turnover intent. As a result, LMX has an indirect significant positive effect on employee turnover intent through emotional self-regulation. This effect is equal to $0.969 * 0.551=0.534$. $\mathrm{R}^{2}$ for employee turnover intent is $76 \%$.

6. Self-monitoring

$$
\begin{gathered}
\text { Employee Turnover Intent }=\beta_{01}+\beta_{11} L M X \\
\text { Employee Turnover Intent }=\beta_{02}+\beta_{12} \text { Self }- \text { Monitoring } \\
\text { Self }- \text { Monitoring }=\beta_{03}+\beta_{13} \text { LMX }
\end{gathered}
$$

Table 7. Path regressions of the self-monitoring component of intercultural competence as the mediating variable between LMX and employee turnover intent

\begin{tabular}{llll}
\hline Model & Estimate & P-Value & $\begin{array}{l}\text { Standard Error of the } \\
\text { Estimate }\end{array}$ \\
\hline $\begin{array}{l}\text { Employee Turnover Intent } \rightarrow \text { LMX } \\
\text { Employee Turnover Intent }\end{array}$ & 0.375 & 0.009 & 0.144 \\
$\begin{array}{l}\text { Self-Monitoring } \\
\text { Self-Monitoring } \rightarrow \text { LMX }\end{array}$ & 0.618 & 0.000 & 0.142 \\
\hline
\end{tabular}


Table 7 shows that LMX has a direct significant positive effect on employee turnover intent. LMX has a direct significant positive effect on self-monitoring. Self-Monitoring has a direct significant effect on employee turnover intent. As a result, LMX has an indirect significant positive effect on employee turnover intent through self-monitoring. This effect is equal to $0.982 * 0.618=0.607$. $\mathrm{R}^{2}$ for employee turnover intent is $76 \%$.

7. Tolerance for ambiguity

$$
\begin{gathered}
\text { Employee Turnover Intent }=\beta_{01}+\beta_{11} L M X \\
\text { Employee Turnover Intent }=\beta_{02}+\beta_{12} \text { Tolerance for Ambiguity } \\
\text { Tolerance for Ambiguity }=\beta_{03}+\beta_{13} \mathrm{LMX}
\end{gathered}
$$

Table 8. Path regressions of the tolerance for ambiguity component of intercultural competence as the mediating variable between LMX and employee turnover intent

\begin{tabular}{llll}
\hline Model & Estimate & P-Value & $\begin{array}{l}\text { Standard Error of the } \\
\text { Estimate }\end{array}$ \\
\hline Employee Turnover Intent $\rightarrow$ LMX & 0.579 & 0.000 & 0.116 \\
$\begin{array}{l}\text { Employee Turnover Intent } \rightarrow \text { Tolerance for } \\
\text { Ambiguity }\end{array}$ & 0.416 & 0.000 & 0.114 \\
Tolerance for Ambiguity $\rightarrow$ LMX & 0.969 & 0.000 & 0.016
\end{tabular}

Table 8 shows that LMX has a direct significant positive effect on employee turnover intent. LMX has a direct significant positive effect on tolerance for ambiguity. Tolerance for ambiguity has a direct significant effect on employee turnover intent. As a result, LMX has an indirect significant positive effect on employee turnover intent through tolerance for ambiguity. This effect is equal to $0.969^{*} 0.416=0.403 . \mathrm{R}^{2}$ for employee turnover intent is $76 \%$.

8. Low need for cognitive

$$
\begin{gathered}
\text { Employee Turnover Intent }=\beta_{01}+\beta_{11} L M X \\
\text { Employee Turnover Intent }=\beta_{02}+\beta_{12} \text { Low Need for Cognitive } \\
\text { Low Need for Cognitive }=\beta_{03}+\beta_{13} \text { LMX }
\end{gathered}
$$

Table 9. Path regressions of the low need for cognitive component of intercultural competence as the mediating variable between LMX and employee turnover intent

\begin{tabular}{llll}
\hline Model & Estimate & P-Value & $\begin{array}{l}\text { Standard Error of the } \\
\text { Estimate }\end{array}$ \\
\hline Employee Turnover Intent $\rightarrow$ LMX & 0.283 & 0.000 & 0.145 \\
Employee Turnover Intent $\rightarrow$ Low Need for & 0.720 & 0.000 & 0.145 \\
Cognitive & 0.971 & 0.000 & 0.013 \\
Low Need for Cognitive $\rightarrow$ LMX &
\end{tabular}

Table 9 shows that LMX has a direct significant positive effect on employee turnover intent. LMX has a direct significant positive effect on low need for cognitive. Low need for cognitive has a direct significant effect on employee turnover intent. As a result, LMX has an indirect significant positive effect on employee turnover intent through low need for cognitive. This effect is equal to $0.971 * 0.720=0.699$. $\mathrm{R}^{2}$ for employee turnover intent is $77 \%$.

9. Cognitive flexibility

$$
\begin{gathered}
\text { Employee Turnover Intent }=\beta_{01}+\beta_{11} L M X \\
\text { Employee Turnover Intent }=\beta_{02}+\beta_{12} \text { Cognitive Flexibility } \\
\text { Cognitive Flexibility }=\beta_{03}+\beta_{13} \mathrm{LMX}
\end{gathered}
$$


Table 10. Path regressions of the cognitive flexibility component of intercultural competence as the mediating variable between LMX and employee turnover intent

\begin{tabular}{llll}
\hline Model & Estimate & P-Value & $\begin{array}{l}\text { Standard Error of the } \\
\text { Estimate }\end{array}$ \\
\hline $\begin{array}{l}\text { Employee Turnover Intent } \rightarrow \text { LMX } \\
\text { Employee Turnover Intent } \rightarrow \text { Cognitive }\end{array}$ & 0.733 & 0.000 & 0.139 \\
Flexibility & 0.259 & 0.065 & 0.140 \\
Cognitive Flexibility $\rightarrow$ LMX & 0.963 & 0.000 & 0.013 \\
\hline
\end{tabular}

Table 10 shows that LMX has a direct significant positive effect on employee turnover intent. LMX has a direct significant positive effect on cognitive flexibility. Cognitive flexibility does not have a direct significant effect on employee turnover intent. As a result, LMX does not have an indirect effect on employee turnover intent through cognitive flexibility. $\mathrm{R}^{2}$ for employee turnover intent is $75 \%$.

The above findings indicate that $\mathrm{H} 1$ is accepted: There is a direct positive relationship between LMX and employee turnover intent. On the other hand, H2 is only partially accepted: There is an indirect relationship between LMX and employee turnover intent in the presence of intercultural competence, except in the case of Cross-cultural Openness and Cognitive Flexibility.

\section{Discussion}

The study attempts to extend the research addressing the effects of LMX on employee turnover intent into new geographical areas, Egypt. This helps enhance our understanding of the LMX - employee turnover intent relationship in an understudied region. Despite the considerable amount of previous research on this issue, we could only find one previous study (Abu Elanain, 2014) that examined a country in the Middle East. To the best of our knowledge, our study is the first to test the mediating effect of intercultural competence on the LMX - employee turnover intent relationship. This will hopefully encourage other researchers to include intercultural competence as one of the mediators when examining the LMX - employee turnover intent relationship besides other commonly used mediators such as job staisfaction.

Unlike the studies that found a U-shaped curvilinear relationship between LMX quality and employee turnover intent (Kim et al., 2010; Harris et al., 2005; Morrow et al., 2005), our results were only able to show that employee turnover intent is highest when LMX quality is good, i.e., there is a positive relationship between LMX and employee leave intent. We found similar results when using intercultural competence as a mediator, with the exception of two (cross-cultural openness and cognitive flexibility) out of the nine components that we used to measure intercultural competence. Our results contradict many Western studies (Schyns et al., 2007; Gerstner \& Day, 1997) that found a negative relationship between LMX and employee leave intent. This contradiction adds more credence to the statement by Collins (2010) that "the exact nature of the relationship between LMX and turnover intent remains equivocal."

\section{Limitations}

The study does have a number of limitations which could have affected our results. First, the data was collected using a questionnaire. This means that the results will depend on the honesty and transparency of the 319 employees who returned the questionnaires. Second, all our participants were employees in Egypt's three telecommunications companies (Vodafone, Etisalat and Orange) which raises concerns regarding common method bias. Third, we examined employee turnover intent instead of actual employee turnovers. Fourth, we chose only nine characteristics out of more than 300 characteristics used in previous research to represent intercultural competence. The results might have varied if different intercultural competence characteristics were chosen.

\section{Future research}

Future studies should examine whether our contradictory results are generalizable to other sectors besides the telecommunications sector in Egypt and if the results hold for the telecommunications sector in other Middle Eastern and/or Western countries. The study could be replicated using other characteristics to represent both LMX and intercultural competence in order to see if the results hold. Researchers should try and examine the reason behind the partial mediation of intercultural competence on LMX - employee turnover intent relationship. 


\section{Implications}

The study's results that contradict the assertions of previous research on the negative relationship between LMX and employee turnover intent, creates a conundrum when it comes to the managerial implications of the study. Usually, one of the implications of these kind of studies would be to stress to managers the importance of having high quality LMX relations with their employees in order to reduce the number of employee turnovers. Our contradicting results do not necessarily lead to contradicting implications. Having high quality LMX relations with employees will allow them to excel at their jobs and as a result be in higher demand in the job market. This will ultimately increase employee turnover intent because the employees have more opportunities. Managers need to develop strategies that will help their companies retain those highly sought after employees. Management researchers should examine the variables that convert the employee turnover intent into becoming actual employee turnovers.

Human Resource departments have a role in holding training sessions for managers in order to stress the importance of maintaining high quality LMX relationships with their employees. It is important that managers understand the LMX theory, its antecedents and outcomes and how this relates to employee leave intent and actual turnovers at their firms. Supervisors should be coached on the importance of creating a team-oriented culture that emphasizes conflict resolution and mutual support between employees. Training sessions should include the importance of mentoring employees, treating them with respect and being attentive to their career development goals.

Management should focus on creating a culture of openness where mutual discussions between employees and their supervisors helps solve problems and alleviate issues that employees might face. Encouraging employees to share their issues and concerns with management will lead to employees being more satisfied with their jobs and as a result having higher commitment to staying with their organizations and reducing turnovers. Management should consider making the career advancement paths very clear to all employees, as having clear goals leads to better performance. Supervision of quality, fairness, flexibility, and feedback are important issues, which have a strong and immediate effect on job performance and employee commitment to their organizations.

\section{Conclusions}

This is one of the few studies that examines the relationship between LMX and employee leave intent in the Middle East. To the best of our knowledge, it is the first study that examines the mediating effect of intercultural competence on LMX - employee turnover intent relationship. The study revealed that there is a significant positive relationship between LMX and employee turnover intent. The results also indicated that there is an indirect relationship between LMX and employee turnover intent in the presence of intercultural competence, except in the case of cross-cultural openness and cognitive flexibility. The study's contribution, limitations, future research opportunities and implications were discussed in the paper.

\section{References}

Abbasi, S., \& Hollman, K. (2000). Turnover: The real bottom line. Public Personnel Management, 29(3), 333-342. https://doi.org/10.1177/009102600002900303

Abu Elanain, H. (2014). Leader-member exchange and intent to turnover: Testing a mediated effects model in a high turnover work environment. Management Research Review, 37(2), 110-129. https://doi.org/10.1108/MRR-09-2012-0197

Adil, M., \& Awais, A. (2016). Effects of leader-member exchange, interpersonal relationship, individual feeling of energy and creative work involvement towards turnover intention: A path analysis using structural equation modeling. Asian Academy of Management Journal, 21(2), 99-133. http://dx.doi.org/10.21315/aamj2016.21.2.5

Ali, M., Lodhi, S., Orangzab, Raza, B., \& Ali, W. (2018). Examining the impact of managerial coaching on employee job performance: Mediating role of work engagement, leader-member-exchange quality, job satisfaction, and turnover intentions. Pakistan Journal of Commerce and Social Science, 12(1), 253-282.

Ang, S., Van Dyne, L., Koh, C., \& Ng, K. (2007). Cultural intelligence: Its measurement and effects on cultural judgment and decision making, cultural adaptation and task performance. Management and Organization Review, 3(3), 335-371. http://dx.doi.org/10.1111/j.1740-8784.2007.00082.x

Arishi, M., Elsaid, A., Dawi, S., \& Elsaid, E. (2018). The impact of socially responsible leadership on employee retention: An exploratory study on Egyptian IT companies. Business \& Management Research, 7(2), 17-33. http://dx.doi.org/doi.org/10.5430/bmr.v7n2p17.

Bluedorn, A. (1982). A unified model of turnover from organizations. Human Relations, 35, 135-153. http://dx.doi.org/10.1177/001872678203500204 
Chiu, C., \& Hong, Y. (2005). Cultural competence: Dynamic processes. In A. Elliot \& C. Dweck $\quad$ (Eds.), Handbook of competence and motivation (pp. 489-505). New York, NY: Guilford.

Collins, M. (2010). The effect of psychological contract fulfillment on manager turnover intentions and its role as a mediator in a casual, limited-service restaurant environment. International Journal of Hospitality Management, 29(4), 736-742. http://dx.doi.org/ 10.1016/j.ijhm.2010.03.005

Cropanzano, R., Dasborough, M., \& Weiss, H. (2017). Affective events and the development of leader-member exchange. Academy of Management Review, 42(2), 233- 258. http://dx.doi.org/10.5465/amr.2014.0384

Cushner, K., \& Mahon, J. (2002). Overseas student teaching: Affecting personal, professional, and global competencies in an age of globalization. Journal of Studies in International Education, 6(1), 44-58. http://dx.doi.org/10.1177/1028315302006001004

Dalessio, A., Silverman, W., \& Schuck, J. (1986). Paths to turnover: A re-analysis and review of existing data on the Mobley, Horner and Hollingsworth turnover model. Human Relations, 39, 245-263. http://dx.doi.org/10.1177/001872678603900305

Dienesch, R., \& Liden, R. (1986). Leader-member exchange model of leadership: A critique and further development. The Academy of Management Review, 11(3), 618-634. https://doi.org/10.2307/258314

Duncan, P., \& Herrera, R. (2014). The relationship between diversity and the multidimensional measure of leader-member exchange (LMX-MDM). Journal of Management Policy and Practice, 15(1), 11-24.

El Farghaly, H., \& Fouad, O. (2013). The impact of labor turnover on the performance of Egyptian organizations in private sector and factors affecting labor turnover. Retrieved from https://www.bartleby.com/essay/Employee-Turnover-in-EgyptP3BWHCE3RZYS

Fantini, A. (2009). Assessing intercultural competence. In D. Deardorff (Ed.), The Sage Handbook of intercultural competence (pp. 456-476). Thousand Oaks, CA: SAGE.

Flickinger, M., Allscher, M., \& Fiedler, M. (2016). The mediating role of leader-member exchange: A study of job satisfaction and turnover intentions in temporary work. Human Resource Management Journal, 26(1), 46-62. http://dx.doi.org/10.1111/1748-8583.12091

Gerstner, C., \& Day, D. (1997). Meta-analytic review of leader-member exchange theory: Correlates and construct issues. Journal of Applied Psychology, 82(6), 827-844. http://dx.doi.org/10.1037/0021-9010.82.6.827

Graen, G. (1976). Role-making processes within complex organizations. In M.D. Dunnette (Ed.), Handbook of Industrial and Organizational Psychology, (pp. 1201-1245). Chicago: Rand McNally.

Graen, G., \& Uhl-Bien, M. (1995). Relationship-based approach to leadership: Development of leader-member exchange (LMX) theory of leadership over 25 years: Applying a multi- level multi-domain perspective. Leadership Quarterly, 6(2), 220-246. http://dx.doi.org/10.1016/1048-9843(95)90036-5

Griffeth, R., Hom, P., \& Gaertner, S. (2000). A meta-analysis of antecedents and correlates of employee turnover: Update, moderator tests, and research implications for the next millennium. Journal of Management, 26, 463-488. http://dx.doi.org/10.1177/014920630002600305

Gross, J., \& John, O. (2003). Individual differences in two emotion regulation processes: Implications for affect, relationships, and well-being. Journal of Personality and Social Psychology, 85(2), 348-362. http://dx.doi.org/10.1037/0022-3514.85.2.348

Gudykunst, W., \& Kim, Y. (2003). Communicating with strangers: An approach to intercultural communication ( $4^{\text {th }}$ ed.). New York, NY: McGraw Hill.

Harris, K., Harris, R., \& Eplion, D. (2007). Personality, leader-member exchange and work outcomes? Journal of Behavioral and Applied Management, 8(2), 92-107.

Harris, K., Kacmar, K., \& Witt, L. (2005). An examination of the curvilinear relationship between leader-member exchange and intent to turnover. Journal of Organization Behavior, 26(4), 363-378. https://doi.org/10.1002/job.314

Hollander, E. (1978). Leadership dynamics: A practical guide to effective relationships. New York, NY: The Free Press.

Inceoglu, I., \& Bartram, D. (2012). Global leadership: the myth of multicultural competency. Industrial and Organizational Psychology, 5(2), 216-47. https://doi.org/10.1111/j.1754-9434.2012.01432.x 
Johnson, J., Lenartowicz, T., \& Apud, S. (2006). Cross-cultural competence in international business: Toward a definition and a model. Journal of International Business Studies, 37(4), 525-543. https://doi.org/10.1057/palgrave.jibs.8400205

Joo, B-K. (2010). Organizational commitment for knowledge workers: The roles of perceived organizational learning culture, leader-member exchange quality, and turnover intention. Human Resource Development Quarterly, 21(1), 69-85. https://doi.org/10.1002/hrdq.20031

Jordan, P., \& Troth, A. (2011). Emotional intelligence and leader member exchange: The relationship with employee turnover intentions and job satisfaction. Leadership \& Organization Development Journal, 32(3), 260-280.https://doi.org/10.1108/01437731111123915

Kim, P., Lee, G., \& Carlson, K. (2010). An examination of the nature of the relationship between leader-member exchange (LMX) and turnover intent at different organizational levels. International Journal of Hospitality Management, 29, 591-597. https://doi.org/10.1080/19368623.2017.1228094

Krackhardt, D. (1990). Assessing the political landscape: Structure, cognition, and power in organizations. Administrative Science Quarterly, 35(2), 342-369. https://doi.org/10.2307/2393394

Kwak, W., \& Choi, S. (2015). Effect of rating discrepancy on turnover intention and leader member exchange. Asia Pacific Journal of Management, 32, 801-824. https://doi.org/10.1007/s10490-015-9414-3

Land, K. (1969). Principles of path analysis. Sociological Methodology, 1, 3-37. https://doi.org/ 10.2307/270879

Lee, J. (2005). Effects of leadership and leader-member exchange on commitment. Leadership \& Organizational Development Journal, 26(7/8), 655. https://doi.org/10.1108/01437730510633728

Liden, R. \& Maslyn, J. (1998). Multidimensionality of leader-member exchange: An empirical assessment through scale development. Journal of Management, 24(1), 43-73. https://doi.org/10.1016/S0149-2063(99)80053-1

Liden, R., Sparrowe, R., \& Wayne, S. (1997). Leader-member exchange theory: The past and potential for the future. Research in Personnel and Human Resources Management, 15, 47-119.

Lustig, M., \& Koester, J. (2010). Intercultural competence: Interpersonal communication $\quad$ across cultures $^{\left(6^{\text {th }}\right.}$ ed.). Boston, MA: Allyn \& Bacon.

Luszczynska, A., Scholz, U., \& Schwarzer, R. (2005). The general self-efficacy scale: Multicultural validation studies. Journal of Psychology, 139(5), 439-457. https://doi.org/10.3200/JRLP.139.5.439-457

Mardanov, I., Sterrett, J., \& Baker, J. (2007). Satisfaction with supervision and member job satisfaction in leader-member exchange: An empirical study in the restaurant industry. Journal of Applied Management and Entrepreneurship, 12(3), 37-56.

McCroskey, J. (1992). Reliability and validity of the willingness to communicate scale. Communication Quarterly, 40, 16-25. https://doi.org/10.13072/midss.511

Morrow, P., Suzuki, Y., Crum, M., Ruben, R., \& Pautsch, G. (2005). The role of leader-member exchange in high turnover work environments. Journal of Managerial Psychology, 20(8), 681-694. https://doi.org/10.1108/02683940510631444

Ross, K. (2008, May). Toward an operational definition of cross-cultural competence from interview data. Patrick AFB, FL: Defense Equal Opportunity Management Institute (DEOMI). Retrieved from http://www.au.af.mil/au/awc/awcgate/deomi/cross_cultural_competence_interviews.pdf

Ross, K., Thornson, C., McDonald, D., \& Arrastia, M. (2009, February). The development of the CCCI: The Cross-Cultural Competence Inventory. Paper presented at the Conference Proceedings of the $7^{\text {th }}$ Biennial Equal Opportunity, Diversity and Culture Research Symposium, Patrick AFB, FL.

Saeed, I., Waseem M., Sikander, S., \& Rizman, M. (2014). The relationship of turnover intention with job satisfaction, job performance, leader member exchange, emotional intelligence and organizational commitment. International Journal of Learning \& Development, 4(2), 242-256. https://doi.org/10.5296/ ijld.v4i2.6100

Scandura, T. (1999). Rethinking leader-member exchange and organizational justice perspective. Leadership Quarterly, 10, 25-40. https://doi.org/10.1016/S1048-9843(99)80007-1

Scandura, T., Graen, G., \& Novak, M. (1986). When managers decide not to decide autocratically: An investigation of leader-member exchange and decision influence. Journal of Applied Psychology, 71, 579-584. http://dx.doi.org/10.1037/0021-9010.71.4.579 
Schwarzer, R., \& Jerusalem, M. (1995). Generalized self-efficacy scale. In J. Weinman, S. Wright, \& M. Johnston (Eds.), Measures in health psychology: A user's portfolio. Causal and control beliefs (pp. 35-37). Windsor, UK: National Foundation for Educational Research-Nelson.

Schyns, B., Torka, N., \& Gossling, T. (2007). Turnover intention and preparedness for change: Exploring leader-member exchange and occupational self-efficacy as antecedents of two employability predictors. Career Development International, 12(7), 660-679. https://doi.org/10.1108/13620430710834413

Sparrowe, R., \& Liden, R. (1997). Process and structure in leader-member exchange. Academy of anagement Review, 22, 522-552. https://doi.org/10.5465/AMR.1997.9707154068

Spitzberg, B., \& Chagnon, G. (2009). Conceptualizing intercultural competence. In D. Deardorff Ed.), The SAGE Handbook of intercultural competence (pp. 2-52). Thousand Oaks, A: SAGE.

Vecchio, R. (1985). Predicting employee turnover from leader-member exchange: A failure to eplicate. Academy of Management Journal, 28(2), 478-485. https://doi.org/10.5465/256213

Vecchio, R., \& Norris, W. (1996). Predicting employee turnover from performance, satisfaction and leader-member exchange. Journal of Business and Psychology, 11(1), 113-125. https://doi.org/10.1007/BF02278260

Wang, Y., Davidson, M., Yakushko, O., Savoy, H., Tun, J., \& Bleiern, J. (2003). The scale of ethnocultural empathy: Development, validation, and reliability. Journal of Counseling Psychology, 50, 221-234. https://doi.org/10.1037/0022-0167.50.2.221

Webster, D., \& Kruglanski, A. (1994). Individual differences in need for cognitive closure. Journal of Personality and Social Psychology, 67(6), 1049-1062. https://doi.org/10.1037/0022-3514.67.6.1049

Wells, J. \& Peachy, J. (2011). Turnover intentions: Do leadership behaviors and satisfaction with the leader matter? Team Performance Management, 17(1/2), 23-40. https://doi.org/10.1108/13527591111114693

Wright, S. (1960). Path coefficients and path regressions: Alternative or complementary concepts? Biometrics, 16(2), 189-202. https://doi.org/10.2307/2527551

Yamane, T. (1967). Elementary sampling theory. Englewood Cliffs, NJ: Prentice Hall.

Zhang, L., Lam, C., \& Deng, Y. (2017). Leader-member exchange and guanxi are not the same: Differential impact of dyadic relationships on fit perceptions, helping behavior, and turnover intention. The International Journal of Human Resource Management, 28(7), 1005-1030. https://doi.org/10.1080/09585192.2015.1128469 